\title{
ANALIZANDO LA TESIS DE LOS DERECHOS IMPLÍCITOS: COMENTARIO A LA SENTENCIA DEL TRIBUNAL CONSTITUCIONAL RECAÍDA SOBRE EL REQUERIMIENTO DE INAPLICABILIDAD ROL N $\mathrm{N}^{\circ}$ 2.408-2013 DE 6 DE MARZO DE 2014
}

\author{
GonZalo CANDia FALCóN*
}

\section{INTRODUCCIÓN}

El objetivo central del presente comentario será analizar la institución de los derechos implícitos a la luz del fallo del Tribunal Constitucional recaído en el recientemente resuelto Rol $\mathrm{N}^{\circ}$ 2.408-2013 ${ }^{1}$. Esta sentencia rechazó declarar inaplicable los artículos 206 del Código Civil y $5^{\circ}$ transitorio de la Ley $\mathrm{N}^{\circ} 19.585$. Esto significó un cambio en la jurisprudencia del tribunal respecto a esta materia. En efecto, desde el año 2009, el tribunal venía declarando inaplicable por inconstitucional la norma del Código Civil señalada. La razón que se esgrimía era que el establecimiento de plazos legales de caducidad para el ejercicio de la acción de reconocimiento de filiación contra los herederos del presunto padre o madre implicaba violar el derecho a la identidad personal. Este derecho no está contemplado expresamente en la Constitución; sin embargo, el Tribunal Constitucional indicó que él representaba un derecho implícito contenido en los artículos $1^{\circ}$ inciso primero y $5^{\circ}$ inciso segundo de la carta fundamental.

Ahora bien, esa doctrina ha venido progresivamente cambiando a partir del mismo año 2009. En efecto, si bien las declaraciones de inaplicabilidad del artículo 206 del Código Civil se han mantenido, su fundamentación ha variado. Hoy los jueces constitucionales prefieren evitar fundar la inaplicabilidad de la norma referida en la existencia de un derecho implícito a la identidad personal. El fallo en comento es parte de ese proceso. En la sentencia del Rol No 2.408-2013, el Tribunal Constitucional rechazó declarar inaplicable el artículo 206 del Código Civil

\footnotetext{
* Doctor en Derecho, Universidad de Georgetown. Profesor de Derecho Constitucional y Derecho Internacional de los Derechos Humanos, Facultad de Derecho, Pontificia Universidad Católica de Chile. Correo electrónico: gfcandia@uc.cl

1 Tribunal Constitucional. 6 de marzo de 2014. Rol No 2.408-2013. "Requerimiento de inaplicabilidad por inconstitucionalidad formulado por la Juez Subrogante del Juzgado de Familia de Pitrufquén respecto del artículo 206 del Código Civil, en causa RIT C-2262012, sobre reconocimiento de paternidad". Disponible en: http://www.tribunalconstitucional.cl/wp/sentencias/busqueda-basica [fecha de visita 13 de abril de 2014].
} 
y el artículo $5^{\circ}$ transitorio de la Ley $\mathrm{N}^{\circ} 19.585$. Ello debido al empate producido al interior del mismo tribunal, el que impidió la conformación de una mayoría. Dentro de los ministros, hubo votos que favorecieron la declaración de inaplicabilidad invocando la existencia de un derecho implícito; otros, en cambio, fueron derechamente partidarios de rechazar el requerimiento.

Aprovechando precisamente el voto favorable a la declaración de inaplicabilidad, comentaremos la tesis de los derechos implícitos. En primer lugar, se determinará el carácter de dichos derechos. En este sentido, indicaremos que los derechos implícitos no son consecuencia de un acto de interpretación judicial, sino una construcción normativa del juez constitucional.

Reconociendo que el juez constitucional tiene potestades para realizar esta construcción en aquellos casos en que se confronta a disposiciones constitucionales amplias y textualmente indeterminadas -tales como el artículo $1^{\circ}$ inciso primero de la Constitución- señalaremos, sin embargo, que el juez no goza de discrecionalidad absoluta para operar en esta área. Por el contrario, el juez constitucional se encuentra limitado por varios factores: (a) los principios del estado de derecho, que buscan dotar a todo sistema jurídico de estabilidad y coherencia; (b) las normas de reforma constitucional contenidas en el capítulo XV de la Constitución, que habilitan únicamente al constituyente derivado para modificar la Ley Suprema; (c) la distribución constitucional de competencias que impone una obligación de autocontrol al juez con el objeto de que este no invada las potestades propias del Congreso Nacional; (d) los derechos expresamente reconocidos por la propia Constitución, y (e) la tradición constitucional nacional relativa a los derechos fundamentales, la cual, no siendo contraria a los imperativos planteados por los absolutos morales y al texto constitucional actual, obliga al juez a preservar la estabilidad del sistema constitucional.

Finalmente, se propondrá que el fallo en comento tácitamente consideró adecuadamente los factores anteriormente mencionados, rechazando esta vez la pretensión de fundar una declaración de inaplicabilidad en la infracción de derechos implícitos. En efecto, la ausencia de una mayoría clara que defendiera esa última posición es prueba de ello.

\section{1) ANTECEDENTES DE LA SENTENCIA}

Con fecha 22 de enero de 2013, Milena Anselmo Cartes, jueza subrogante del Juzgado de Letras y Familia de Pitrufquén, requirió al Tribunal Constitucional pronunciarse respecto de la inaplicabilidad por inconstitucionalidad de los artículos 206 del Código Civil y $5^{\circ}$ transitorio de la Ley $\mathrm{N}^{\circ}$ 19.585. Ello en el contexto de una causa de reclamación de 
paternidad cuya resolución aún se encontraba pendiente. La requirente argumentaba que la aplicación de las normas legales en cuestión a la causa pendiente podría producir efectos inconstitucionales en la medida que las disposiciones privaban, en la práctica, al demandante del derecho a la identidad y a la igualdad ante la ley².

El artículo 206 del Código Civil establece los presupuestos básicos para que una persona pueda entablar una acción de reclamación de paternidad o maternidad en contra de los herederos del presunto padre o madre. La norma señala que solo se podrá iniciar la acción contra los herederos en caso que (a) el hijo fuese póstumo o bien si alguno de los padres hubiese fallecido dentro de los ciento ochenta días posteriores al parto; y (b) siempre que la acción sea ejercida dentro del plazo de tres años contados desde la muerte del presunto padre o madre o bien, si el hijo fuese incapaz, contados a partir del momento en que este hubiese adquirido capacidad plena.

Por otro lado, el artículo $5^{\circ}$ transitorio de la Ley $\mathrm{N}^{\circ} 19.585$ estableció un sistema transitorio que reguló las situaciones generadas con anterioridad a la entrada en vigencia de la ley. En ese sentido, la norma dispuso que, tratándose de hijos póstumos o hijos cuyos padres hubiesen fallecido ciento ochenta días después del parto, la acción de filiación contra los herederos será posible solo en la medida que (a) la demanda fuese presentada dentro del plazo de un ańo contado a partir de la entrada en vigencia de la ley, y (b) siempre que no hubiese sentencia ejecutoriada que rechace la pretensión de paternidad o maternidad.

En la causa pendiente ante el juzgado de letras y familia de Pitrufquén, la demanda de reconocimiento de filiación no matrimonial fue presentada por la madre de un menor de edad nacido el 5 de febrero de 1996 en contra de los herederos del presunto padre. Este había fallecido el 16 de octubre de 1996 y, por tanto, el menor en cuestión no tenía la calidad de hijo póstumo (puesto que el presunto padre vivía al momento del nacimiento). Por otro lado, el presunto padre falleció con posterioridad a los ciento ochenta días después del parto. Por tanto, de acuerdo a la jueza requirente, la aplicación del artículo $5^{\circ}$ de la Ley $\mathrm{N}^{\circ} 19.585$ en conjunción con el artículo 206 del Código Civil a la gestión pendiente implicaba el rechazo de la demanda, lo que infringía el derecho a la identidad y a la igualdad ante la ley del menor representado. Esto por cuanto el menor se vería imposibilitado de acceder a la verdad biológica acerca de sus orígenes ${ }^{3}$.

El Tribunal Constitucional rechazó el recurso de inaplicabilidad por cuanto, concluida la vista de la causa, hubo un empate de votos. Por tan-

TC. $R o l N^{\circ} 2.408-2013$, pp. 2-5.

TC. $R o l N^{\circ} 2.408-2013$, p. 4. 
to, se tuvo por rechazado el recurso en la medida que no se alcanzó la mayoría exigida constitucionalmente para ser acogido ${ }^{4}$. Los votos se dividieron de la siguiente forma. A favor de acoger el requerimiento estuvieron los ministros Marisol Peña, Hernán Vodanovic, Gonzalo García y Juan José Romero; por el rechazo, en cambio, estuvieron los ministros Carlos Carmona, Domingo Hernández, Iván Aróstica y María Luisa Brahm.

Los argumentos ofrecidos para acoger el requerimiento de inaplicabilidad fueron, básicamente, dos. El primero dijo relación con la infracción del principio de igualdad ante la ley establecido en el artículo $19 \mathrm{~N}^{\circ} 2$ de la Constitución. De acuerdo al voto redactado por la Ministra Marisol Peńa, los requisitos exigidos por el artículo 206 del Código Civil para ejercer la acción de reconocimiento de filiación contra los herederos del presunto padre o madre establecen una discriminación injustificada respecto de quienes no cumplen los presupuestos de la acción. En efecto, el establecer un plazo para ejercer esa acción "entraña una exigencia arbitraria que limita injustificadamente el derecho del hijo a reclamar su filiación y lo sitúa en una desventaja respecto de quienes su presunto padre efectivamente murió dentro de tal plazo" 5 .

Similar problema de constitucionalidad existiría respecto del artículo $5^{\circ}$ de la Ley $N^{\circ} 19.585$ de acuerdo a lo indicado por el voto de la Ministra Peña. El establecimiento de un plazo para ejercer las acciones de filiación no matrimonial "introduce una diferencia de trato entre aquellos hijos que pueden reclamar su paternidad o maternidad y aquellos que no pueden hacerlo por intentar la respectiva acción transcurrido el plazo de un año desde la vigencia de dicha ley"'. Adicionalmente, el plazo en cuestión infringiría también los criterios propios del juicio de proporcionalidad. Ello por cuanto el artículo $5^{\circ}$ de la Ley $\mathrm{N}^{\circ} 19.585$ protegería de forma exclusiva el interés particular de los herederos pero no así el derecho que tendría toda persona de conocer su filiación biológica. En ese sentido, la norma impugnada no optimizaría ambos intereses de forma proporcional ${ }^{7}$.

El segundo argumento invocado por el voto que buscaba acoger el recurso de inaplicabilidad fue que las normas impugnadas infringían el artículo $5^{\circ}$ inciso segundo de la Constitución en relación a los artículos $3^{\circ}, 5^{\circ}$ y 18 de la Convención Interamericana de Derechos Humanos y los artículos 16 y 17 del Pacto Internacional de Derechos Civiles y Políticos.

En este respecto, el voto redactado por la Ministra Peña señaló que, tal como el Tribunal Constitucional lo había establecido en ocasiones previas, el ordenamiento reconocía el derecho a la identidad personal, aun cuando dicho derecho no se encontrase expresamente reconocido

\footnotetext{
TC. Rol N² 2.408-2013, p. 5 .

TC. Rol N² 2.408-2013, p. 7.

TC. Rol N².408-2013, p. 10.

TC. Rol N².408-2013, p. 12.
} 
en el texto constitucional. Ello por cuanto el derecho a la identidad era un derecho implícito, esto es, tácitamente reconocido por vía de deducción a partir de los artículos $1^{\circ}, 5^{\circ}$ inciso segundo y $19 \mathrm{~N}^{\circ} 4$ de la Carta Fundamental. Asimismo, el voto razonó, el derecho en cuestión se encontraba reconocido en tratados internacionales ratificados por Chile y que se encontraban vigentes ${ }^{8}$. En ese sentido, el derecho a la identidad se encontraría estrechamente vinculado a la posibilidad de conocer la verdad biológica y gozar del reconocimiento social que permite afirmar la dignidad personal' ${ }^{9}$.

Los ministros Carmona y Hernández votaron por el rechazo de la inaplicabilidad. En el voto redactado por el Ministro Carmona se ofrecieron dos argumentos para dicho rechazo. Primero, que la discusión sujeta al conocimiento del tribunal versaba sobre la más apropiada interpretación legal de un precepto y, por tanto, no constituía un conflicto de constitucionalidad ${ }^{10}$. Luego, no correspondía al Tribunal Constitucional sino al juez ordinario resolver el conflicto en cuestión ${ }^{11}$. En segundo lugar, el Ministro Carmona señaló que el artículo $5^{\circ}$ inciso segundo de la Constitución "no es una habilitación de potestades para que cualquier órgano del Estado, bajo el pretexto de invocar su obligación de respeto y promoción, exceda e invada la competencia de otros órganos del Estado" ${ }^{2}$. Por tanto, los jueces del fondo eran los llamados a definir una interpretación que permitiera conciliar los intereses en juego y promover los derechos esenciales de la persona humana ${ }^{13}$.

Finalmente, el voto redactado por el Ministro Carmona indicó que la distinción establecida por el artículo $5^{\circ}$ de la Ley $\mathrm{N}^{\circ} 19.585$ era plenamente razonable en la medida que la norma buscaba "consolidar situaciones que la Ley $\mathrm{N}^{\circ} 19.585$ estableció, sobre todo en materia patrimonial"14. En este respecto, el legislador tenía la potestad de poder establecer plazos de caducidad al ejercicio de acciones legales en la medida que "no hay reglas en la Constitución que prohíban establecer estos plazos"15. Por el contrario, de acuerdo al Ministro Carmona, es la misma Constitución la que exigiría la regulación de regímenes legales de transición en conformidad al artículo $19 \mathrm{~N}^{\circ} 26^{16}$.

Los Ministros Aróstica y Brahm fueron también partidarios de rechazar el requerimiento. En un voto redactado por la Ministra Brahm,

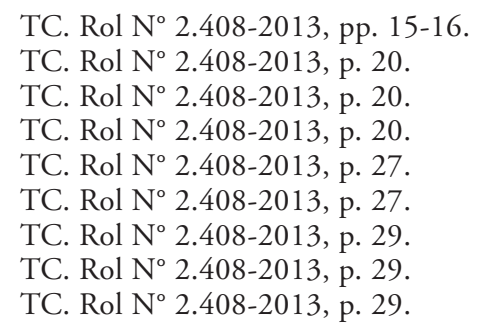


los ministros en cuestión argumentaron que las distinciones introducidas tanto por el artículo 206 del Código Civil como del artículo $5^{\circ}$ de la Ley $\mathrm{N}^{\circ} 19.585$ eran plenamente razonables y justificadas. Ello en la medida que el legislador "sí tuvo presente fundamentos objetivos y razonables al introducir excepciones a la caducidad [de la acción de reclamo de filiación respecto de los herederos del presunto padre o madre]" 17.

\section{2) EL DERECHO IMPLÍCITO A LA IDENTIDAD PERSONAL. CONCEPTUALIZACIÓN}

El fallo en comento del Tribunal Constitucional nos brinda la oportunidad para analizar una estructura conceptual cuyo reconocimiento ha ido paulatinamente difundiéndose en la doctrina constitucional chilena. Me refiero al concepto de derechos implícitos. En efecto, el Tribunal Constitucional ha utilizado el concepto de derechos implícitos para automáticamente derivar ciertas garantías no cubiertas por el catálogo de derechos contenido por el capítulo tercero de la Carta Fundamental. De esa forma, el tribunal -por ejemplo- ha afirmado la existencia de un derecho implícito a acceder a la información pública, cuya raíz se encontraría en los artículos $4^{\circ}, 8^{\circ}$ y $19 \mathrm{~N}^{\circ} 12^{18}$.

Asimismo, el tribunal, en una serie de fallos en los cuales ha decidido respecto de la inaplicabilidad del artículo 206 del Código Civil, ha reconocido el derecho implícito a la identidad personal, entendiéndose por tal el derecho de la persona a conocer sus orígenes biológicos. Dicho derecho ha sido, a su vez, derivado de dos fuentes: (a) el principio constitucional que reconoce la igualdad en dignidad y derechos de las personas (artículo $1^{\circ}$ inciso primero de la Constitución) y (b) el principio constitucional que reconoce que la soberanía, en especial aquella ejercida por el Poder Legislativo, es limitada por "los derechos esenciales de la persona humana" reconocidos por la Constitución y por "los tratados internacionales ratificados por Chile y que se encuentren vigentes" (artículo $5^{\circ}$ inciso segundo).

En cuanto este último derecho implícito, el Tribunal Constitucional ha señalado que el derecho a la identidad personal es una derivación del mandato constitucional de proteger la dignidad de las personas. En ese sentido, si la persona no puede acceder al conocimiento biológico acerca

17 TC. Rol N².408-2013, p. 31.

18 Tribunal Constitucional. 9 de agosto de 2007. Rol Nº 634-2007. "Requerimiento de inaplicabilidad respecto del artículo 13 de la Ley No 18.575, presentado por la Corte de Apelaciones de Valparaíso en la causa caratulada Lean Casas Cordero, Carlos Eric con Director Nacional de Aduanas Rol No 2336-06, seguida ante ese mismo Tribunal”. Disponible en: http://www.tribunalconstitucional.cl/wp/sentencias/busqueda-basica [fecha de visita 25 de abril de 2014], pp. 28-33. 
de su origen debido, por ejemplo, al establecimiento de un plazo de caducidad para el ejercicio de las acciones de filiación correspondientes, entonces el legislador infringe el derecho a la identidad personal en la medida que la restricción constituye una afrenta a la dignidad personal. En ese sentido, el Tribunal Constitucional ha definido el derecho a la identidad personal en los siguientes términos:

El reconocimiento del derecho a la identidad personal -en cuanto emanación de la dignidad humana- implica la posibilidad de que toda persona pueda ser ella misma y no otra, lo que se traduce en que tiene derecho a ser inscrita inmediatamente después de que nace, a tener un nombre desde dicho momento y, en la medida de lo posible, a conocer a sus padres y a ser cuidada por ellos $(\ldots)^{19}$.

Asimismo, el tribunal ha explicado el estrecho lazo que existiría entre identidad y dignidad en cuanto reconocimiento social:

La estrecha vinculación entre el derecho a la identidad personal y la dignidad humana es innegable, pues la dignidad solo se afirma cuando la persona goza de la seguridad de conocer su origen y, sobre esa base, puede aspirar al reconocimiento social que merece $(\ldots)^{20}$.

El razonamiento del Tribunal Constitucional ha sido el siguiente: en la medida que el acceso a la verdad biológica respecto de la filiación de las personas constituye un derecho derivado del principio constitucional de protección de la dignidad humana, entonces debe ser considerados de aquellos "derechos esenciales" que representan un límite a la acción del legislativo. Por otro lado, el tribunal ha argumentado que, incluso si no se considerara que el derecho a la identidad se encuentra implícito en algún precepto constitucional, este debiera ser reconocido en la medida que se encuentra implícito en otras garantías contenidas en tratados internacionales de derechos humanos, tales como la Convención Interamericana de Derechos Humanos o la Convención sobre los Derechos del Niño. Este es, precisamente, el argumento que se encuentra detrás del voto suscrito por los Ministros Peña, Romero y Vodanovic, quienes afirman sin ambages que "el derecho a la identidad personal constituye un derecho implícitamente reconocido en nuestro ordenamiento en base a lo dispuesto en los artículos $1^{\circ}, 5^{\circ}$ inciso segundo y $19 \mathrm{~N}^{\circ} 4$ de la ley suprema" ${ }^{21}$. Luego,

19 Tribunal Constitucional. Rol No 1.340-09. "Requerimiento de inaplicabilidad por inconstitucionalidad del Juez Presidente del Juzgado de Familia de Pudahuel, señor Carlos Marcelo Casaula Mezzano respecto del artículo 206 del Código Civil, en la causa RIT No C-111-2009, seguida por investigación/reclamación de paternidad, caratulada "Muñoz con Muñoz". Disponible en: http://www.tribunalconstitucional.cl/wp/sentencias/busquedabasica [fecha de visita 13 de abril de 2014] p. 9.

20 TC. Rol N ${ }^{\circ} 1.340-09$, p. 9.

21 TC. $R o l N^{\circ} 2.408-2013$, p. 16. 
el legislador no podría establecer barreras que pudiesen impedir a las personas el derecho a hacer judicialmente efectivo ese derecho. Precisamente por eso es que, en el criterio de los ministros referidos, el artículo 206 del Código Civil y el artículo $5^{\circ}$ de la Ley $\mathrm{N}^{\circ} 19.585$ debieran declararse inaplicables para el caso concreto.

\section{3) ANÁLISIS CRÍTICO DE LA TESIS DE LOS DERECHOS IMPLÍCITOS}

En este comentario no haremos consideraciones respecto de lo acertado de incluir un derecho a la identidad personal en el texto implícito de la Constitución. Tampoco es nuestra idea pronunciarnos acerca del mérito de la opción de política pública que se encuentra detrás de las normas impugnadas por la jueza de letras y familia de Pitrufquén ${ }^{22}$. Por el contrario, nuestro propósito es efectuar algunas reflexiones en torno a la categoría de los derechos implícitos.

\section{1) LOS DERECHOS IMPLÍCITOS EN EL DERECHO COMPARADO: Estados Unidos y AUSTRalia. CoRTES internaCiOnaleS DE DERECHOS HUMANOS}

La idea de derechos implícitos no es nueva en el panorama constitucional comparado. En efecto, esta categoría constitucional comenzó a ser utilizada con fuerza en los Estados Unidos a partir de los años sesenta para justificar el reconocimiento jurisprudencial de pretensiones sociales sin expreso reconocimiento constitucional tales como la posibilidad de gozar de libre movilidad dentro y fuera de los estados, contraer matrimonio, la protección de la privacidad, la comercialización y consumo de anticonceptivos, la práctica del aborto y la eutanasia. Para justificar el reconocimiento constitucional de algunas de esas pretensiones, la Corte Suprema norteamericana ha señalado que existen derechos en la "penumbra" de aquellas garantías expresamente reconocidas en el Bill of Rights ${ }^{23}$. Dichos derechos constituyen una categoría especial, la categoría de los "derechos no enumerados" o derechos implícitos. Las fuentes normativas utilizadas para justificar la existencia de esta categoría han sido: (a) la IX enmienda, que señala que "la enumeración de ciertos derechos en la Constitución no debe ser

\footnotetext{
22 Para un análisis en este respecto: Rodríguez Grez, Pablo (2010): "Comentario de la sentencia del Tribunal Constitucional de 29 de septiembre de 2009, mediante la cual se declara inaplicable el artículo 206 del código civil”. En Fermandois Vohringer, Arturo y Delaveau Swett, Rodrigo (editores): Sentencias destacadas 2009. Santiago: Instituto Libertad y Desarrollo, pp. 117-138.

23 Corte Suprema de los Estados Unidos de América. 7 de junio de 1965. 381 US 479. "Griswold con Connecticut". Disponible en: http://www.law.cornell.edu/supremecourt/ text/381/479 [fecha de visita 13 de abril de 2014] p. 483.
} 
utilizada para negar o restringir otros derechos retenidos por el pueblo", y (b) la XIV enmienda que establece que nadie puede ser privado de su vida, libertad y propiedad sin un "debido proceso".

Australia es otro ejemplo comparado de particular importancia para el estudio de la concepción de derechos implícitos. La Constitución federal australiana incluye el reconocimiento expreso de los siguientes derechos: (a) la libertad religiosa, (b) el derecho a ser juzgado por un jurado tratándose de delitos federales; (c) el derecho a ser resarcido en caso de expropiación y $(\mathrm{d})$ el derecho a no ser discriminado en base a la residencia de cada ciudadano. Sin embargo, la Constitución australiana carece de un bill of rights sistemático, construido de acuerdo a los modelos norteamericano y europeo. A pesar de aquello, las cortes australianas, a partir de la década de los noventa, han comenzado a reconocer derechos implícitos derivados tanto del texto constitucional como de la estructura representativa de gobierno. Entre esos derechos, se encuentran, por ejemplo, el derecho a la libertad de expresión política y los derechos a la libertad de movimiento y asociación ${ }^{24}$.

A nivel supranacional, el Tribunal Europeo de Derechos Humanos fue pionero en la aplicación de la tesis de los derechos implícitos al Convenio. En Golder con Reino Unido, el tribunal razonó que el artículo $6^{\circ} \mathrm{del}$ Convenio -que establece el derecho a que toda causa, una vez iniciada, fuese oída de forma equitativa, pública y dentro de un plazo razonable por un tribunal establecido por la ley- incluía de forma implícita un derecho de acceso a las cortes ${ }^{25}$. Ello aun cuando -tal como lo señaló el juez sir Gerald Fitzmaurice en su voto disidente- la intención original de los redactores del convenio fue precisamente excluir cualquier reconocimiento de un derecho general de acceso a las cortes ${ }^{26}$. Asimismo, la Corte Interamericana de Derechos Humanos, basado en el derecho a la privacidad y autodeterminación personal, descubrió el derecho implícito que tenían las parejas de acceder a tratamientos de fertilización in vitro financiados por el Estado 27 .

24 STONE, Adrienne (2006): "Australia's constitutional rights and the problem of interpretative disagreement". En Campbell, Tom; Goldsworthy, Jeffrey, y Stone, Adrienne (editores): Protecting rights without a bill of rights. Institutional performance and reform in Australia. Aldershot: Ashgate Publishing Limited, pp. 137-157.

25 Tribunal Europeo de Derechos Humanos. 21 de febrero de 1975. Aplicación $N^{\circ} 4.451$ 70. "Golder con Reino Unido". Disponible en: http://hudoc.echr.coe.int/sites/eng/pages/ search.aspx?i=001-57496\#\{“itemid”:[“001-57496”]\} [fecha de visita 13 de abril de 2014].

26 TEDH. Golder con Reino Unido, p. 50.

27 Corte Interamericana de Derechos Humanos. 28 de noviembre de 2012. Serie C-257. "Artavia Murillo y otros con Costa Rica". Disponible en: http://www.corteidh.or.cr/docs/ casos/articulos/seriec_257_esp.pdf [fecha de visita 13 de abril de 2014]. Para un análisis acerca de los derechos implícitos en la Convención Americana de Derechos Humanos, ver: Gross Espiell, Héctor (2000): "Los derechos humanos no enunciados o no enumerados en el constitucionalismo americano y el artículo 29.c) de la Convención Americana sobre 
En todos estos casos, el reconocimiento de derechos implícitos ha ido de la mano de un creciente activismo judicial tanto en Estados Unidos, Australia y Europa. En efecto, las cortes han ido descubriendo en los derechos implícitos un mecanismo para ampliar su capacidad de decisión e, incluso, modificar tácitamente el texto constitucional. No es, en ese sentido, extraño que la discusión en torno a la tesis de los derechos implícitos o no enumerados hubiese surgido en el contexto de casos altamente controvertidos, donde la pretensión de los actores era que los jueces cambiaran de forma radical el entendimiento del Derecho. Esos fueron, por ejemplo, los contextos de casos como Griswold con Connecticut ${ }^{28}$, Roe con Wade $^{29}$ y Washington con Glucksberg ${ }^{30}$, en los Estados Unidos.

\section{2) DERECHOS IMPLÍCITOS EN EL TRIBUNAL CONSTITUCIONAL CHILENO: ¿INTERPRETACIÓN O CONSTRUCCIÓN?}

En relación a la tesis de los derechos implícitos, el Tribunal Constitucional chileno parece ir moviéndose en la dirección norteamericana y australiana. En efecto, de forma muy tímida primero ${ }^{31}$ y luego de forma cada vez más asertiva, nuestra máxima magistratura constitucional ha afirmado la existencia de un corpus de derechos implícitos no textuales contenidos en la Carta Fundamental. Esto demanda un serio análisis que precisa determinar cuáles son los presupuestos sobre los que reposa la teoría de los derechos implícitos.

Antes de ello, una necesaria precisión. Los derechos implícitos derivados por las cortes constitucionales de principios constitucionales textualmente vagos y radicalmente abstractos no representan instancias de interpretación constitucional. Por el contrario, ellos representan construcciones normativas. Esta distinción es crítica para comprender adecuadamente el contexto de nuestra discusión. Toda interpretación constitucional supone discernir el contenido semántico del texto. Muchas veces, el texto constitucional es ambiguo, esto es, tiene más de un sentido preciso.

Derechos Humanos". En Anuario iberoamericano de justicia constitucional $N^{\circ}$ 4. Madrid: Centro de Estudios Políticos y Constitucionales, pp. 145-172.

28 CS EUA, 381 US 479.

29 Corte Suprema de los Estados Unidos de América. 22 de enero de 1973. 410 U.S. 113. "Roe con Wade". Disponible en: http://www.law.cornell.edu/supremecourt/ text/410/113 [fecha de visita 14 de abril de 2014].

30 Corte Suprema de los Estados Unidos de América. 26 de junio de 1997. 521 U.S. 702. "Washington y otros con Glucksberg y otros". Disponible en: http://www.law.cornell.edu/ supct/html/96-110.ZS.html [fecha de visita 14 de abril de 2014].

31 Tribunal Constitucional. 30 de octubre de 1995. Rol No 226-1995. "Requerimiento de Diputados respecto del artículo $1^{\circ}$, inciso tercero; artículo $9^{\circ}$, inciso primero; artículo 20 , inciso segundo, y artículo 43, inciso segundo, del proyecto de ley sobre "Libertad de expresión, información y ejercicio del periodismo". Disponible en: http://www.tribunalconstitucional.cl/wp/sentencias/busqueda-basica [fecha de visita 13 de abril de 2014] p. 24. 
En aquellos casos, el juez constitucional debe indicar cuál es el sentido que se adecua más al texto y al espíritu de la norma constitucional ${ }^{32}$.

Sin embargo, muchas veces el texto constitucional no es solo ambiguo, sino que también es vago. Esto es, el texto es incapaz por sí solo de trazar algún tipo de regla que oriente al juez. En estos casos, la sola interpretación no basta para resolver un caso, porque el contenido semántico de la norma no es suficiente para resolverlo. Entonces, se hace necesario determinar ese texto mediante la especificación de una regla, por ejemplo. En ese caso, el juez suplementa la norma debido a su radical indeterminación. Es en estas circunstancias que se indica que el texto constitucional no debe ser solo interpretado (esto es, determinar el sentido y alcance del texto en cuestión), sino también construido. Tal como Keith Whittington señala, la "construcción constitucional es el proceso por medio del cual (...) se suplementa la interpretación constitucional (...)"33. En la medida que dicha construcción no signifique una infracción de las reglas establecidas por la misma Constitución, la construcción permite "extender la aplicación de la Constitución a la vida política y a implementar el texto constitucional poniéndolo en práctica"34.

Ahora bien, la naturaleza jurídica de la construcción es de tipo legislativo. En efecto, la construcción judicial de normas no busca solo discernir el significado de una cláusula constitucional abierta, sino también crear reglas que permitan la aplicación de aquella a un caso específico. Es por ello que dichas construcciones judiciales son esencialmente políticas y legislativas ${ }^{35}$.

Este es precisamente el caso de principios constitucionales tales como el deber de respeto y promoción de la dignidad humana. El texto del artículo $1^{\circ}$ inciso primero en este respecto establece un estándar de actuación para los órganos del estado. Sin embargo, el texto en cuestión no es capaz por sí solo de resolver un caso concreto en la medida que, dada la naturaleza de la norma, el texto no especifica ninguna regla en concreto. Es por ello que se requiere especificar el mandato por medio de una decisión de tipo legislativa. En relación a este punto, Pablo Contreras indica que la cláusula del artículo $1^{\circ}$ inciso primero "es de un altísimo contenido abstracto e indeterminado y que requiere un ejercicio profun-

\footnotetext{
32 Para un análisis más profundo respecto de la distinción, ver: Sollum, Lawrence (2010). "The interpretation-construction distinction". Constitutional Commentary $\mathrm{N}^{\circ} 27$, pp. 95-118. Disponible en: http://scholarship.law.georgetown.edu/cgi/viewcontent. cgi?article $=1675 \&$ context=facpub [fecha de visita 13 de abril de 2014].

33 Whittington, Keith (2011): "On pluralism within originalism". En Huscroft, Grant y Miller, Bradley W. (editores): The challenge of originalism. Theories of constitutional interpretation. Cambridge: Cambridge University Press, pp. 70-87, p. 75. (La traducción es nuestra).

34 Whittington (2011) 75. (La traducción es nuestra).

35 Whittington, Keith (1999) Constitutional Interpretation. Textual Meaning, Original Intent and Judicial Review. Lawrence: Kansas University Press, 299 pp., p. 11.
} 
do de interpretación para su aplicación"36. En ese sentido, la apelación judicial a la dignidad humana para identificar derechos podría permitir que "cualquier pretensión subjetiva se pueda alojar bajo la amplísima y vaga cláusula de dignidad" 37 . Ello sería fuente de numerosos "problemas metodológicos" 38 .

Dichos problemas metodológicos no ocurren solo en Chile. Christopher McCrudden ilustra como los jueces constitucionales de otras latitudes también ha empezado a utilizar el concepto de dignidad como fuente para construir nuevos derechos constitucionales. Ello ha ocurrido, por ejemplo, en Israel y el Reino Unido ${ }^{39}$. Sin embargo, ese uso ha sido altamente controversial. Primero, porque no existe un acuerdo generalizado en las jurisdicciones constitucionales del mundo acerca del corazón de las exigencias jurídicas planteadas por la dignidad humana ${ }^{40} \mathrm{y}$, segundo, porque los jueces han utilizado el concepto como una "cortina de humo" para imponer al legislador sus propias preferencias en materia de políticas públicas sin articular suficientemente la sustancia de sus decisiones ${ }^{41}$.

Cuando el Tribunal Constitucional deriva del reconocimiento de la dignidad humana el derecho implícito a conocer la verdad biológica acerca de nuestra filiación, el tribunal no está interpretando, sino construyendo el artículo $1^{\circ}$ inciso primero de la carta fundamental. Dicha construcción excede el ámbito de la interpretación y supone no solo descubrir el sentido y alcance de la norma, sino también realizar un juicio de prudencia que es eminentemente normativo y creador. En resumen: cuando el Tribunal Constitucional construye una norma vaga y abstracta que implica ir más allá de la determinación del sentido semántico del texto, lo que el tribunal hace es actuar como un legislador judicial. Este es, precisamente, el caso de los derechos implícitos; ellos no son implícitos, en el sentido que los jueces descubren algo necesario que subsiste detrás de la norma, sino que representa una instancia de creación judicial en el ámbito de lo posible.

Pablo Contreras trata de evitar el debate en torno a la noción de derechos implícitos por medio de una nueva conceptualización. Para Contreras, toda identificación de derechos requiere de una fuente positiva representada por "una norma positiva de jerarquía superior (...) que atribuya tal potestad subjetiva" ${ }^{42}$. Dicha norma positiva deben ser los

\footnotetext{
36 Contreras Vásquez, Pablo (2011): “¿Derechos implícitos? Notas sobre la identificación de normas de derecho fundamental”. En Núñez Leiva, José Ignacio (editor): Nuevas perspectivas en derecho público. Santiago: Librotecnia, 149-185, p. 172.

Contreras (2011) 173.

Contreras (2011) 181.

McCrudden, Christopher (2008). "Human dignity and judicial interpretation of human rights". The European Journal of International Law, Vol. 19 N 4, pp. 655-724, p. 721.

McCrudden (2008) 723.

McCrudden (2008) 722.

Contreras (2011) 176.
} 
derechos enumerados en la carta fundamental o bien los derechos establecidos en tratados internacionales ${ }^{43}$. En esto, Contreras concuerda con lo manifestado por Humberto Nogueira, en el sentido que los derechos implícitos contenidos en tratados internacionales de derechos humanos formarían parte del bloque de constitucionalidad ${ }^{44}$.

Reconociendo la necesidad de partir desde una norma positiva, Contreras plantea que es posible evitar los conflictos que surgen a partir de la noción de derechos implícitos si entendemos que los jueces, tratándose de la aplicación de derechos constitucionales cuyo texto es amplio e indeterminado, se limitan a definir "las normas adscritas" 45 a cada derecho fundamental positivo. Dicho ejercicio de concreción, señala Contreras, supondría "determinar el sentido y alcance de estas normas, así como sus condiciones de aplicación” ${ }^{4}$. La concreción permitiría, Contreras concluye, evitar "recurrir a construcciones argumentativas que implican o presuponen derechos" ${ }^{7}$. Por tanto, "no habría creaciones de nuevos derechos por autoridades que carecen de competencia para la reforma de la [Constitución]" ${ }^{48}$. En ese sentido, la concreción constituiría una mera "descalada en grados de abstracción (...) para efectuar el control de constitucionalidad" 49 .

Si bien -como se verá- comparto con Contreras su preocupación en torno a los riesgos institucionales que suponen la adopción de la tesis de los derechos implícitos, creo que su conceptualización de lo que él denomina concreción constitucional es inexacta.

Es claro que normas iusfundamentales abiertas e indeterminadas requieren de un juicio de concreción o determinatio para ser aplicadas por la jurisdicción constitucional ${ }^{50}$. Sin embargo, dado el carácter radicalmente indeterminado de la norma, lo que el juez hace no es meramente interpretarla, desentrańando su sentido y alcance, tal como lo argumentan los jueces al momento de descubrir derechos implícitos. Por el contrario, el juez construye la norma por medio de un acto de especificación en la medida que el texto no permite interpretar, dada su amplitud. La concreción a la que Contreras se refiere, entonces, no representa una ins-

43 Contreras (2011) 176.

44 Nogueira Alcalá, Humberto (2007). "Los derechos humanos contenidos en tratados de derechos humanos como parte del parámetro de control de constitucionalidad: la sentencia rol No 786-2007 del tribunal constitucional”. Estudios Constitucionales, Año $5 \mathrm{~N}^{\circ}$ 2, pp. 457-466, p. 457.

Contreras (2011) 178.

Contreras (2011) 178.

Contreras (2011) 181 .

Contreras (2011) 181 .

Contreras (2011) 181 .

Finnis, John (2011) Natural Law and Natural Rights. $2^{\text {nd }}$ edition. Oxford: Oxford University Press, 494 pp., pp. 284-289. 
tancia de interpretación judicial, sino de construcción normativa que, en la mayoría de los casos, tendrá carácter legislativo. En ese sentido, dichas concreciones no representan simples desarrollos jurisprudenciales de normas previamente existentes cuyo sentido se ha mantenido constante a lo largo del tiempo. Suponer aquello sería, como Finnis plantea, "un cuento de hadas" 51 . Por el contrario, las concreciones judiciales a las que refiere Contreras no son meras adscripciones de un precepto constitucional, sino derechamente ellas representan reglas legislativas impuestas por los jueces constitucionales.

Por tanto, creo que la pregunta fundamental en este debate no es si los jueces constitucionales pueden o no crear reglas jurídicas. En muchos casos ellos lo hacen. Y en muchos de esos casos, esa creación normativa no es necesariamente inspirada en la intención de los jueces de abusar de su poder. En efecto, muchas veces la producción judicial de reglas no se debe al espíritu activista de los jueces sino al modelo normativo de estándares abiertos e indeterminados elegido por el constituyente o el legislador. La discusión, entonces, debe centrarse -asumiendo la existencia de dichos estándares- en: (a) definir si existen o no límites para la labor creativa de los jueces en un estado constitucional, y (b) determinar cuáles son los factores que definen precisamente esos límites.

Ahora bien, y retornando al caso concreto, la interrogante es si el Tribunal Constitucional, al momento de construir una norma constitucional abierta como aquella representada por el artículo $1^{\circ}$ inciso primero de la Constitución, puede generar toda clase de derechos "implícitos" a partir de la misma.

Una primera respuesta a la referida interrogante podría provenir de aquellos sectores que plantean -en palabras de Charles Evans Hughes, juez de la Corte Suprema de los Estados Unidos- que "nosotros estamos bajo el imperio de la Constitución, pero la Constitución es aquello que los jueces dicen que es" 52 . Bajo esta concepción, los jueces constitucionales tendrían un poder discrecional absoluto para construir preceptos constitucionales vagos y abiertos en la medida que las cortes serían la última autoridad llamada a determinar el contenido de la carta fundamental. Esto, a su vez, permitiría actualizar y adaptar el texto constitucional a las nuevas demandas promovidas por distintos grupos sociales que no pueden utilizar los procedimientos de reforma constitucional formal para in-

\footnotetext{
51 Finnis, John (2011): "Adjudication and legal change". En Finnis, John: Philosophy of law: Collected essays. Volume IV. Oxford: Oxford University Press, pp. 397-403, p. 399. (La traducción es nuestra).

52 Hughes, Charles Evans (1916) Addresses. 2 ${ }^{\text {nd }}$ edition. New York: G.P Putnam's Sons, 363 pp., p. 185. (La traducción es nuestra).
} 
cluir sus pretensiones en el texto de la Constitución en razón de su incapacidad de generar las mayorías cualificadas necesarias para la reforma ${ }^{53}$.

La tesis indicada plantea serios problemas desde la perspectiva del rule of law. Uno de los aspectos centrales de la noción de estado de derecho es que las decisiones judiciales deben ser congruentes con el texto de la ley positiva. Dicha congruencia obliga al juez decidir en conformidad al texto de esa ley ${ }^{54}$. Esto busca restringir la discrecionalidad judicial, que debe limitarse a la interpretación y aplicación del texto ofrecido por el legislador. Los jueces están llamados primariamente a aplicar las reglas del Derecho y no a erigirse en legisladores o constituyentes. De esta forma se logra que la autoridad judicial se encuentre, como todos los órganos del Estado, sujeta al Derecho. Si ello no fuese así, entonces el principio de sujeción al Derecho de todas las autoridades -reconocida por lo demás en el artículo $6^{\circ}$ inciso primero de la Constitución- sería una ilusión.

Una posible réplica al planteamiento anteriormente señalado podría ser la siguiente: sí, es cierto que los jueces deben ajustar sus decisiones al texto de la norma constitucional; sin embargo, dicha obligación existe solo en aquellos casos en que la Constitución establezca reglas específicas para ser aplicadas. Por ejemplo, una regla de esa naturaleza sería la contenida en el artículo 65 de la Constitución que establece que todo proyecto de ley sobre administración financiera y presupuestaria del Estado es de iniciativa exclusiva del Presidente de la República y que, por tanto, el Congreso Nacional solo puede aceptar, disminuir o rechazar los gastos asociados a esas iniciativas, nunca aumentarlas. Tratándose, por tanto, de reglas constitucionales, el juez constitucional debería limitarse a aplicarlas a casos concretos, tal como ocurrió con el mencionado artículo 65 en el denominado caso "postnatal" 55 .

Sin embargo, y la réplica continúa, tratándose de la aplicación de preceptos abiertos e indeterminados, el juez constitucional tendría facultades completamente discrecionales para construir reglas legislativas a partir de estándares tales como "la Constitución asegura a todas las personas: la igualdad ante la ley". En ese sentido, la indeterminación del texto tácitamente otorgaría facultades a los jueces para discrecionalmente descubrir todo tipo de derechos implícitos en las referidas cláusulas.

53 Ackerman, Bruce (1991) We The People: Foundations. Cambridge: The Belknap Press of Harvard University Press, 369 pp., pp. 50-57.

54 Fuller, Lon L. (1969) The Morality of Law. $2^{\text {nd }}$ edition. New Haven: Yale University Press, 262 pp., p. 81.

55 Tribunal Constitucional. 20 de julio de 2011. Rol Nº 2.025-2011. "Requerimiento del Presidente de la República respecto de la inconstitucionalidad de la actuación del Senado y la consecuente modificación introducida por este al artículo 197 bis del Código del Trabajo contenido en el proyecto de ley que crea el permiso postnatal parental y modifica el Código del Trabajo". Disponible en: http://www.tribunalconstitucional.cl/wp/sentencias/busquedabasica [fecha de visita 13 de abril de 2014]. 
Si bien es cierto que tratándose de normas textualmente indeterminadas los jueces constitucionales gozan de un margen de discreción para generar reglas legislativas a partir del texto de la Constitución, dicho margen no es absoluto. Por el contrario, dicho margen es limitado. Ello siempre y cuando aceptemos que el estado de derecho -y su necesidad de establecer límites al ejercicio del poder estatal- es un concepto sustantivo y central a todo modelo de gobierno constitucional. Tal como señala Joseph Raz, "en cada caso en cual las cortes crean Derecho, ellas también aplican leyes que restringen y guían sus procesos de producción de Derecho. [Estos casos] son parcialmente (...) no regulados, y [por tanto] las cortes, al momento de distinguir casos o bien de dejar sin efecto precedentes previos, están circunscritas y restringidas por limitaciones legales" 56 . En este respecto, si las cortes fueran completamente discrecionales para construir preceptos constitucionales amplios, entonces los tribunales no se encontrarían plenamente sujetos al Derecho, sino a las meras preferencias subjetivas de quienes los integran.

Otra cuestión diversa, y que no trataremos en este comentario, dice relación con el órgano constitucional que está llamado preferentemente a construir las disposiciones constitucionales textualmente indeterminadas. En la medida que esa especificación implica realizar un acto normativo, es el legislador quien está primariamente llamado a construir la norma vaga por medio de normas jurídicas de alcance general. Ello porque: (a) el proceso legislativo goza de la suficiente representatividad, transparencia y publicidad que permite a los ciudadanos el debido acceso al debate y, (b) las potestades de la legislatura le permiten efectuar reformas de tipo general y prospectivo, cuestión que es difícil de lograr para las cortes ${ }^{57}$. Esto no significa que los jueces no puedan construir esas normas indeterminadas respecto de casos concretos; sin embargo, dicha creación está fuertemente limitada por su carácter particular (aplicable solo a un caso específico) y su naturaleza retroactiva en muchos casos. A continuación pasaremos a examinar otros factores que restringen de forma importante la función creadora del juez constitucional.

\section{3) LIMITACIONES A LA CONSTRUCCIÓN DE DERECHOS IMPLíCITOS: EL ESTADO DE DERECHO}

Las limitaciones a las cuales se encuentra sujeto el juez constitucional al momento de construir derechos implícitos son de tipo institucional o sustantivo. Las limitaciones institucionales pueden ser genéricas o especí-

\footnotetext{
56 Raz, Joseph (2012): "Law and value in adjudication". En Raz, Joseph: The Authority of Law. $2^{\text {nd }}$ edition. Oxford: Oxford University Press, 340 pp., p. 195. (La traducción es nuestra).

$57 \quad$ Raz (2012) 200.
} 
ficas. Las genéricas dicen relación con la obligación que tienen las cortes de sujetarse a los principios representativos de la desiderata del estado de derecho. Las específicas refieren a los límites planteados al juez por el capítulo XV de la Constitución chilena, el que establece los procedimientos y mecanismos específicos para reformar la Constitución. Una segunda restricción institucional específica está dada por el ámbito de competencias específicas definida por la propia Constitución para los diversos órganos estatales. Finalmente, las cortes constitucionales se encuentran, desde una perspectiva sustantiva, limitadas en torno a su capacidad para definir derechos implícitos por dos factores. Primero, el texto de los derechos fundamentales efectivamente declarados en la Constitución y, segundo, la tradición constitucional de cada comunidad política en torno a dichos derechos.

\subsection{1) La desiderata del estado de derecho}

En primer lugar, las cortes -como todo órgano del estado- se encuentran sujetas al Derecho, en conformidad a lo indicado en el artículo $6^{\circ}$ inciso primero de la carta fundamental. Esta exigencia de sujeción es la base del estado de derecho. Ahora bien, el estado de derecho se identifica, primariamente, con las condiciones bajo las cuales un sistema legal es capaz de funcionar adecuada y decentemente. Dichas condiciones exigen que las normas legales: (a) no tengan carácter retroactivo; (b) sean susceptibles de ser cumplidas por sus destinatarios; (c) sean promulgadas públicamente; (d) sean claras; (e) sean coherentes las unas con las otras; (f) tengan la estabilidad suficiente para orientar a las personas en sus procesos de toma de decisiones; $(\mathrm{g})$ sean originadas en procesos predeterminados que, a su vez, sean claros, estables y de aplicación general $\mathrm{y}$, finalmente, (h) que las autoridades llamadas a legislar, administrar y aplicar el Derecho lo hagan de forma consistente y buscando siempre la congruencia entre el texto de la norma y la aplicación respectiva ${ }^{58}$.

En principio, parecería que estas obligaciones afectan especialmente al legislador, pero ello no es así. La desiderata del estado de derecho también afecta a los jueces, particularmente cuando ellos actúan como legisladores al momento de construir normas vagas y amplias. En este sentido, las exigencias del estado de derecho buscan limitar la discrecionalidad judicial en un contexto en que el solo texto de la norma no es suficiente para alcanzar ese objetivo. Entonces, los jueces constitucionales, por ejemplo, no podrían crear derechos implícitos cambiando seriamente sus propios precedentes, afectando la coherencia del esquema de derechos constitucional o bien declarando como derechos ciertas pretensiones que

FINNIS (2011) 270-271. 
atentan directamente contra garantías constitucionales reconocidas expresamente en el texto constitucional.

Por tanto, tal como lo indica Lawrence Sollum, en todos aquellos casos en los cuales el texto de la norma constitucional es vago e indeterminado normativamente, los jueces constitucionales deben construir la norma de una forma consistente con el resto de las disposiciones constitucionales y la estructura propia de la Constitución. Si a pesar de ello la vaguedad persiste y el análisis de la intención del constituyente no permite orientar la construcción, entonces los jueces deben optar por adoptar un criterio decisorio que minimice su discrecionalidad y maximice la estabilidad y predictibilidad exigidas por el estado de derecho ${ }^{59}$.

Esto exige de parte de los jueces constitucionales un sentido de disciplina institucional que se traduce en la obligación de las cortes de preservar el principio de separación de poderes tan caro para cualquier sistema de gobierno constitucional. Dentro de dicho esquema, la creación de reglas jurídicas por parte de jueces no representa el caso central de la producción del Derecho, sino un caso periférico ${ }^{60}$. En efecto, el caso focal de la producción del Derecho corresponde al proceso legislativo llevado a cabo, al menos en Chile, por el Congreso Nacional y el Presidente de la República como órganos colegisladores.

\subsection{2.) El capítulo XV de la Constitución: procedimientos de reforma constitucional}

Una segunda limitación institucional para la creación judicial de derechos es el capítulo XV de la Constitución. Este contiene una serie de disposiciones que regulan los mecanismos y las formas por las cuales se reforma la carta fundamental. La aprobación de cualquier reforma se encuentra sujeta a quórums especiales. Tratándose de la modificación del capítulo III, que incluye el catálogo de derechos, el artículo 127 inciso segundo exige la votación favorable de dos tercios de los diputados y senadores en ejercicio. ¿Por qué la Constitución establece este quórum supramayoritario para la aprobación de este tipo de reformas? La respuesta es simple. Es porque el constituyente ha querido que todo acuerdo que implique la modificación del capítulo de garantías fundamentales alcance

59 Sollum, Lawrence (2006). "The Supreme Court in bondage: constitutional stare decisis, legal formalism, and the future of unenumerated rights". University of Pennsylvania Journal of Constitutional Law, Vol. 9, pp. 155-208, p. 185.

60 Para un análisis respecto a la distinción entre casos "centrales" y "periféricos" ver: FinNIs (2011) 9-11. Respecto a las razones por las cuales el Derecho legislado constituye el caso "central" de legislación desde la perspectiva del estado de derecho, véase: Yowell, Paul (2012). "Legislación, common law, y la virtud de la claridad". Revista Chilena de Derecho, Vol. $39 \mathrm{~N}^{\circ}$ 2, pp. 418-512, p. 503-511. 
el mayor consenso político posible. Esto para proteger los derechos de las minorías políticas y dotar de estabilidad al sistema institucional.

Ese propósito del constituyente podría verse fácilmente burlado mediante la creación judicial de derechos constitucionales. En efecto, el Tribunal Constitucional podría encontrar derechos implícitos que podrían modificar tácitamente el texto constitucional ya sea a través de agregar al catálogo pretensiones contradictorias con los derechos fundamentales declarados (pensemos, por ejemplo, en el caso hipotético que el tribunal pudiese encontrar un derecho implícito de la mujer para abortar a su hijo) o bien modificando el texto del capítulo III por medio de la adición de nuevos derechos que no necesariamente se encuentran en contradicción con alguna de las garantías declaradas. Una tercera hipótesis podría ser la simple modificación del alcance de los derechos declarados. En estos tres casos, el Tribunal Constitucional opera ya no como un simple legislador, sino como constituyente, asumiendo las funciones que la carta fundamental asigna exclusivamente al Congreso Nacional y al Presidente de la República. En este sentido, los jueces constitucionales no podrían -argumentando que interpretan la Constitución- modificarla. Toda reforma del texto de la Constitución requiere del cumplimiento de estándares y procedimientos formales contenidos en el capítulo XV de la Constitución. Dichos estándares y procedimientos permiten asegurar, además, la expresión de la voluntad democrática del constituyente derivado.

La doctrina nacional ha sido sensible a este problema. Eduardo Aldunate, por ejemplo, ha señalado que la aceptación de la tesis de los derechos implícitos implicaría ignorar el carácter normativo de la regla de reforma especial de derechos constitucionales contenida en el artículo 127 inciso segundo de la carta fundamental ${ }^{61}$.

Jeffrey Goldsworthy ha advertido un fenómeno que ocurre al momento que los jueces constitucionales crean derechos invocando el texto de la carta fundamental. Goldsworthy indica que en aquellos casos, las cortes reforman la Constitución "alegan[do] no estar haciéndolo"62. Generalmente, los jueces no indican que ellos crean derechos al momento de incluir nuevas pretensiones al catálogo de garantías constitucionales. Ellos saben que eso significaría infringir gravemente la ley fundamental poniendo en juego la legitimidad democrática de su decisión. Es por eso que, a nivel comparado, cuando las cortes crean derechos modificando el texto o la práctica constitucional, ellos argumentan siempre estar interpretando fielmente el texto de la carta fundamental. Esa ha sido la experiencia

61 Aldunate Lizana, Eduardo (1998) Derechos fundamentales. Santiago: LegalPublishing, 439 pp., p. 346.

62 Goldsworthy, Jeffrey (2011): “The case for originalism”. En Huscroft, Grant y Miller, Bradley W. (editores): The challenge of originalism. Theories of constitutional interpretation. Cambridge: Cambridge University Press, pp. 42-69, p. 56. (La traducción es nuestra). 
norteamericana, en la cual la Corte Suprema -al momento de resolver casos tan controversiales como Roe con Wade ${ }^{63}$ o Lawrence con Texas ${ }^{64}$ - ha afirmado que ella simplemente se limita a interpretar las cláusulas constitucionales. En esa misma dirección, Goldsworthy señala que cuando las cortes constitucionales crean derechos, ellas evitan utilizar esa terminología, afirmando que solo "han descubierto dichos derechos en el texto de la Constitución, sin agregar nada a la misma" ${ }^{65}$. Esto, concluye Goldsworthy, "ciertamente indica que los jueces constitucionales comprenden que ellos carecen de una autoridad específica para cambiar la Constitución"66.

En resumen: si el Tribunal Constitucional reforma el capítulo III de la Constitución por medio de sus decisiones, especialmente en aquellos casos que configura como derechos pretensiones incompatibles con los derechos fundamentales expresamente declarados, infringe la propia carta fundamental y violenta los mecanismos democráticos de reforma incluidos en el capítulo XV.

\subsection{3) La distribución de competencias institucionales}

Una segunda limitación institucional específica a la creación de derechos constitucionales por vía judicial está representada por la distribución específica de competencias establecida por la Constitución. Tal como lo indicó el voto particular emitido por los Ministros Carmona y Hernández en el fallo en comento, "las competencias del Tribunal Constitucional las da el ordenamiento jurídico. Más si sus atribuciones son de derecho estricto" 67 . En ese sentido, el tribunal "debe actuar con corrección funcional, es decir, debe respetar el reparto de competencias entre los distintos órganos del estado"68. Por tanto, tratándose de normas constitucionales principiales, esto es, amplias y textualmente no específicadas, toda construcción normativa en base a aquellas debe ser prudente y limitada en cuanto su contenido. Por ejemplo, respecto del artículo $5^{\circ}$ inciso segundo, que establece el deber de respeto y promoción de los derechos esenciales que emanan de la naturaleza humana a todos los órganos del estado, este deber debe ser asumido por el Tribunal Constitucional "desde sus propias atribuciones" 69 .

\footnotetext{
63 CS EUA, 410 U.S. 113.

64 Corte Suprema de los Estados Unidos de América. 26 de junio de 2003. 539 U.S. 558. "Lawrence y otros con Texas". Disponible en: http://www.law.cornell.edu/supct/html/02102.ZS.html [fecha de visita 14 de abril de 2014].

65 Goldsworthy (2011) 56. (La traducción es nuestra).

66 Goldsworthy (2011) 56. (La traducción es nuestra).

67 TC. $R o l N^{\circ} 2.408-2013$, p. 20.

68 TC. Rol No $2.408-2013$, pp. 23-24.

69 TC. Rol N $2.408-2013$, p. 27.
} 
Por tanto, termina de razonar el voto de los ministros Carmona y Hernández, ni el artículo $1^{\circ}$ inciso primero ni el artículo $5^{\circ}$ inciso segundo de la Constitución podrían considerarse como habilitaciones tácitas de nuevas potestades para el Tribunal Constitucional, por cuanto dichas habilitaciones podrían exceder las suyas declaradas en el artículo 93 de la Constitución o bien podrían invadir competencias propias de otros órganos, tales como el Congreso Nacional ${ }^{70}$.

También Eduardo Aldunate ha planteado el problema que significaría para la institucionalidad la creación de derechos constitucionales por vía judicial. Ello implicaría

Investir a los órganos jurisdiccionales no solo una facultad y deber de tutela respecto a entidades innominadas, sino que, y en el caso de la jurisdicción constitucional, dotarla de facultades para alzarse en contra de la actuación legislativa, sobre la base de proposiciones iusfundamentales sin respaldo constitucional positivo ${ }^{71}(\ldots)$ alterando de este modo de manera definitiva el carácter normativo de la Constitución en la distribución de competencias entre legislador y Tribunal Constitucional ${ }^{72}$.

Las reflexiones del voto de los Ministros Carmona y Hernández expresan una idea muy clara: el Tribunal Constitucional es un órgano jurisdiccional llamado a interpretar y aplicar la Constitución. Por tanto, los jueces constitucionales no pueden excederse en sus funciones y ejercer facultades constitucionales que son propias del poder constituyente derivado, ni siquiera invocando los artículos $1^{\circ}$ y $5^{\circ}$ de la carta fundamental. Si bien existen para el Tribunal Constitucional obligaciones derivadas de esos preceptos, las mismas deben ser cumplidas dentro del ámbito de competencias que la Constitución establece para el tribunal. Esa distribución de competencias constitucionales debe mover a las cortes constitucionales a ser muy prudentes al momento de analizar la posibilidad de crear derechos constitucionales por medio de la tesis de los derechos implícitos.

\subsection{4) La existencia de derechos fundamentales declarados en la Constitución}

En cuanto los límites sustantivos a la creación de derechos constitucionales por vía judicial, el primero de ellos está representado por los derechos fundamentales expresamente declarados por la Constitución. Ellos

\footnotetext{
$70 \quad$ TC. $R o l N^{\circ} 2.408-2013$, p. 27.

Aldunate (1998) 345.

Aldunate (1998) 346. Similar consideración en Contreras (2011) 173.
} 
operan como un límite al juez constitucional en la medida que dicho juez no podrá encontrar en el texto de la ley fundamental derechos implícitos que fueren incompatibles con el texto del capítulo III de la Constitución. Un ejemplo típico dice relación con un posible uso de la tesis de los derechos implícitos para incluir en el catálogo de derechos pretensiones tales como el acceso libre al aborto o la permisión de la tortura en casos en los cuales la seguridad nacional lo demande. En esos casos, tanto el texto como la comprensión generalizada del artículo $19 \mathrm{~N}^{\circ} 1$ de la Constitución servirían como freno a la acción de un juez constitucional desbocado. Así, por lo demás, lo ha entendido el propio Tribunal Constitucional cuando tempranamente afirmó que, aun cuando se entienda que el catálogo de derechos del artículo III no es exhaustivo, ello no es razón para que se reconozcan por vía jurisprudencial pretensiones que "implique[n] una violación a las normas fundamentales"73.

\subsection{5) La tradición constitucional en torno a los derechos}

Asimismo, la tradición constitucional -esto es la interpretación y la construcción de los derechos fundamentales realizada tanto por el legislador, los tribunales y la doctrina- deben servir de límite al reconocimiento de derechos implícitos en la medida que dicha tradición no signifique una infracción patente y arbitraria de los principios mínimos de justicia implícitos en los absolutos morales. En la medida que esa tradición no se oponga a esas exigencias, entonces es válida y debe constituir un factor a ser considerado por el juez constitucional. Esto es una demanda del estado de derecho, el que busca generar la estabilidad necesaria para que las personas puedan ordenar y planificar sus decisiones personales o comunitarias adecuadamente. En este sentido, el cambio radical y abrupto de esa tradición por parte de los tribunales constitucionales podría afectar seriamente la necesaria continuidad exigida por la desiderata del estado de derecho.

Esta idea ha sido reconocida en el derecho comparado. Una de las fuentes constitucionales más utilizada por los litigantes norteamericanos para promover la creación de nuevos derechos constitucionales por vía judicial era (y es) la XIV enmienda. Esta norma establece que "ningún Estado podrá privar a las personas de su vida, libertad, o propiedad sin un debido proceso; ni tampoco podrá negar a las personas sujetas a su jurisdicción de la igual protección de la leyes." Pues bien, un grupo de personas recurrió a la Corte Suprema de los Estados Unidos alegando que las normas estatales que prohibían la eutanasia representaban una privación arbitraria de la libertad entendida como autonomía personal. El "dere-

TC. Rol N²26-1995, p. 24. 
cho" a decidir respecto al momento de su muerte constituía, de acuerdo al recurrente, un derecho implícito en la XIV enmienda. Estos fueron los hechos fundamentales del caso Washington con Glucksberg ${ }^{74}$.

La Corte Suprema, en un voto de mayoría redactado por el Chief Justice Rehnquist rechazó el argumento del recurrente. En efecto, la Corte -buscando limitar su propia discrecionalidad para encontrar derechos implícitos en la XIV enmienda en la medida que la norma por sí no establecía suficientes criterios para "decidir responsablemente"75- estableció que todo análisis acerca de los derechos implícitos contenidos en la enmienda requería considerar primeramente "la historia de la nación, las tradicionales legales (del país) y las prácticas (constitucionales)" "76. En ese sentido, Rehnquist afirmó que "por más de 700 años la tradición angloamericana del common law ha criminalizado o desaprobado tanto el suicidio como el auxilio al suicidio"77. En la medida que el derecho implícito al suicidio "no estaba profundamente enraizado en la historia y tradición de la nación" 78 , ni tampoco "estaba implícito en la noción de libertad ordenada [de forma que] la libertad y la justicia podrían existir si [la pretensión] fuera sacrificada"79, la acción constitucional debía rechazarse.

El subtexto del voto redactado por Rehnquist busca imponer disciplina al decision-making judicial. Normas constitucionales textualmente indeterminadas pueden representar un incentivo para que litigantes y jueces promuevan ciertas agendas políticas por medio de las cortes constitucionales, en la medida que las mismas no establecen criterios específicos que puedan guiar la decisión del juez. En la ausencia de ese criterio específico, los jueces deben considerar factores como la tradición y prácticas constitucionales como un instrumento para orientar sus decisiones, evitando todo ejercicio abusivo de la discrecionalidad judicial al momento de descubrir derechos implícitos en disposiciones tales como la IX o la XIV enmienda. Ello no busca sino salvaguardar la sujeción de las cortes al derecho, aspecto esencial de todo modelo decente de estado de derecho.

\subsection{6) Variación jurisprudencial: de los derechos implícitos al texto constitucional}

Para concluir, es de justicia señalar que la jurisprudencia del Tribunal Constitucional chileno en relación a fundar declaraciones de inaplicabilidad del artículo 206 del Código Civil en un derecho implícito a la iden-

CS EUA, 521 U.S. 702.

CS EUA, 521 U.S. 702, p. 720. (La traducción es nuestra).

CS EUA, 521 U.S. 702, p. 710. (La traducción es nuestra).

CS EUA, 521 U.S. 702, p. 711. (La traducción es nuestra).

CS EUA, 521 U.S. 702, p. 721. (La traducción es nuestra).

CS EUA, 521 U.S. 702, p. 721. (La traducción es nuestra). 
tidad personal ha ido cambiando. Si bien el primer fallo funda su razonamiento en la existencia de dicho derecho implícito ${ }^{80}$, posteriormente dichas declaraciones de inaplicabilidad se han ido fundando de forma exclusiva en la infracción del derecho a la igualdad contenido en el artículo $19 \mathrm{~N}^{\circ} 2$ de la Constitución, siguiendo la opinión contenida en el voto particular redactado por el Ministro Raúl Bertelsen en el fallo Rol Nº 1.340-2009 ${ }^{81}$. Ejemplo de ello son las sentencias del Tribunal Constitucional recaídas sobre los Roles $\mathrm{N}^{\circ} 1.537-2009^{82}, 1.563-2009^{83}$ y $1.656-2010^{84}$. El fallo en comento debe, por lo tanto, leerse dentro del referido contexto. Pareciera que el Tribunal Constitucional -a pesar de lo decidido en la sentencia recaída sobre el Rol No 1.340-2009- está evitando declarar la inaplicabilidad del artículo 206 del Código Civil basándose en la infracción de un derecho implícito a la identidad personal. De hecho, la mencionada tesis no fue capaz de imponerse esta vez, debiendo rechazarse el requerimiento presentado por la Jueza Subrogante de Familia de Pitrufquén.

¿Cómo interpretar esa evolución jurisprudencial? Me atrevo a proponer una hipótesis. Creo que el Tribunal Constitucional ha comprendido que la tesis de los derechos implícitos puede significar, en manos de magistrados sin disciplina institucional, una grave complicación para el modelo constitucional chileno. Ello por cuanto la tesis genera demasiados incentivos para un potencial ejercicio ilimitado de la discrecionalidad judicial por parte de los mismos jueces constitucionales. Ello en la medida que las normas textualmente indeterminadas de la Constitución no ofrecen per se una orientación segura como criterio decisorio para las mismas cortes. Esto crea demasiados espacios para concretar normas principiales cuya implementación admite diversas formas legislativas, todas ellas razonables en la medida que no impliquen una infracción directa e intencional de absolutos morales o bien de reglas constitucionales expresas.

80 TC. Rol N $1.340-2009$.

81 TC. Rol No 1.340-2009, pp. 30-31.

82 Tribunal Constitucional. 16 de noviembre de 2009. Rol N 1.537-2009. "Requerimiento de inaplicabilidad por inconstitucionalidad de Carlos Marcelo Casaula Mezzano, respecto de los artículos 206 del Código Civil y $5^{\circ}$ transitorio, inciso cuarto final de la Ley 19.585, en RIT No C - 4688 - 2008 del Juzgado de Familia de Pudahuel.” Disponible en: http:// www.tribunalconstitucional.cl/wp/sentencias/busqueda-basica [fecha de visita 13 de abril de $2014]$

83 Tribunal Constitucional. 1 de diciembre de 2009. Rol Nº 1.563-2009. "Requerimiento de inaplicabilidad por inconstitucionalidad presentado por el Juzgado de Familia de Valdivia, respecto del artículo 206 del Código Civil, en los autos RIT C-966-2009, sobre reconocimiento de paternidad." Disponible en http://www.tribunalconstitucional.cl/wp/ sentencias/busqueda-basica [fecha de visita 26 de abril de 2014].

84 Tribunal Constitucional. 22 de marzo de 2010. Rol N 1.656-2010. "Requerimiento de inaplicabilidad presentado por Nel Greeven Bobadilla, Juez de Familia de Pudahuel, respecto del artículo 206 del Código Civil, en causa RIT C-3479 - 2009 y Ruc 09-2-0335964-8 del Juzgado de Familia de Pudahuel.” Disponible en http://www.tribunalconstitucional.cl/ $\mathrm{wp} /$ sentencias/busqueda-basica [fecha de visita 26 de abril de 2014]. 
Este esfuerzo de disciplina institucional del Tribunal Constitucional debe ser aplaudido. Esto en la medida que él mismo busca resguardar la coherencia de nuestro sistema constitucional desde una perspectiva competencial y de respeto hacia los principios básicos de todo estado de derecho.

\section{CONCLUSIÓN}

Detrás de la discusión acerca de los derechos implícitos se encuentra otra mucho más profunda respecto a la extensión de la discrecionalidad de la cual goza el juez constitucional para construir estándares textualmente abiertos e indeterminados. De hecho, la discusión sobre los derechos implícitos es, al final, una discusión acerca del ejercicio de la discrecionalidad de las cortes constitucionales. En el presente comentario, y a propósito del fallo Rol $\mathrm{N}^{\circ} 2.408-2013$, hemos querido aproximarnos al tema desde la perspectiva ofrecida por la noción clásica de estado de derecho. Dentro de esa noción, la capacidad de los jueces para operar discrecionalmente es limitada tanto por la distribución de competencias constitucionales como por los derechos reconocidos tanto por el texto de la carta fundamental como por la tradición y las prácticas constitucionales.

La cuestión que surge es ¿por qué realmente limitar la discrecionalidad del juez constitucional al momento de descubrir derechos implícitos en la Constitución? ¿Por qué esto podría ser relevante para los ciudadanos comunes y corrientes? Desde una perspectiva institucional, el uso indiscriminado de la tesis de los derechos implícitos, tal como lo afirma Sollum, podría afectar gravemente la percepción que las personas tienen de la autoridad judicial ${ }^{85}$. Si los jueces comienzan a ponderar las ventajas y desventajas de crear derechos implícitos sin considerar fielmente el texto de la Constitución, entonces ipor qué los ciudadanos no podrían hacer lo mismo? ¿Por qué los ciudadanos, al momento de tomar sus decisiones, no podrían evaluar también los costos y beneficios de obedecer al derecho con independencia del texto de la ley? En ese sentido, la relación de reciprocidad que sirve de base a la noción de estado de derecho se quebraría $^{86}$. Finalmente, la facilidad con que los jueces pudiesen ignorar la letra de la Constitución puede gravemente devaluarla ante la ciudadanía. Y ese es, ciertamente, un costo institucional demasiado alto para pagar.

\footnotetext{
85 Sollum (2006) 177.

86 Fuller (1969) 40. Véase también: Finnis (2011) 272-273.
} 